\title{
Highly Efficient Hydrogen Sensors Based on Pd Nanoparticles Supported on Boron Nitride Coated ZnO Nanowires
}

\author{
Matthieu Weber, ${ }^{\ddagger}{ }^{\dagger}$ Jin-Young Kim, ${ }^{\S,}{ }^{\dagger}$ Jae-Hyoung Lee, ${ }^{\S}$ Jae-Hun Kim,${ }^{\S}$ Igor latsunskyi, ${ }^{\times}$Emerson \\ Coy, ${ }^{\times}$Philippe Miele, ${ }^{\neq, \alpha}$ Mikhael Bechelany, ${ }^{\neq, *}$ and Sang Sub Kim ${ }^{\S, *}$
}

\begin{abstract}
High selectivity and sensitivity were measured using a novel type of sensor device, based on ZnO nanowires (NWs) coated with a thin layer of boron nitride (BN) decorated with palladium nanoparticles (NPs). Vapor-Liquid-Solid (VLS) growth and Atomic Layer Deposition (ALD) routes, two scalable technologies, have been used for the synthesis of the sensing device nanomaterials. X-Ray Photoelectron Spectroscopy (XPS), Electron Energy Loss Spectroscopy (EELS), Energy-dispersive X-ray (EDX) spectroscopy and Transmission Electron Microscopy (TEM) studies revealed the presence of both the $5 \mathrm{~nm}$ layer of $\mathrm{BN}$ and metallic Pd NPs around the ZnO NWs. The nanomaterials were then integrated within a miniaturized sensor device in order to measure their performance for $\mathrm{H}_{2}$ detection at different concentrations and temperatures, in the presence of various gases such as $\mathrm{C}_{6} \mathrm{H}_{6}, \mathrm{C}_{7} \mathrm{H}_{8}, \mathrm{C}_{2} \mathrm{H}_{5} \mathrm{OH}$, and $\mathrm{CH}_{3} \mathrm{COCH}_{3}$. High hydrogen response signals of 12.28 ( \pm 0.61$)$ have been measured, even for $\mathrm{H}_{2}$ concentrations as low as 10 ppm, confirming the efficiency of the novel sensor Pd/BN/ZnO NWs design. Due to the beneficial synergistic effect of $\mathrm{ZnO}, \mathrm{BN}$ and $\mathrm{Pd}$ nanomaterials, the new sensing device clearly outperformed other sensors based on ZnO NWs. In addition, the sensor was resistant to humidity, and hydrogen gas could be detected for concentrations as low as $0.5 \mathrm{ppm}$. The high performance obtained with the novel Pd/BN/ZnO NWs based sensor along with its easy gas phase processing open new perspectives and opportunities for the sensing community, and will hopefully promote the hydrogen economy.
\end{abstract}

\section{Introduction}

Hydrogen gas is vital in many chemical processes and plays a crucial role for upcoming transportation technologies. In fact, hydrogen is considered as one of the best clean energy carriers which could contribute to tackle the major environmental issues our society is facing. ${ }^{1-3}$ As the first world scale hydrogen production unit dedicated to the hydrogen energy markets is currently being built, ${ }^{4}$ there are still issues that need to be solved before mass adoption. A leakage of hydrogen could lead to unwanted and disastrous consequences, as it may cause highly damaging explosions. ${ }^{5,6}$ Moreover, hydrogen is a colorless, odorless and tasteless gas, and human nose cannot sense it. 7,8 Therefore, an efficient monitoring of traces of hydrogen has become crucial, and the development of highly sensitive, reliable, fast and precise hydrogen sensors is of great importance for the production, storage and use of this upcoming clean energy carrier.

Typically, the combination of both high sensitivity and selectivity characterizes a high performance sensor. As the sensing mechanism is directly related to the adsorption of gases at the functional material surface - changing its electrical conductivity semiconductor metal oxides are the most used sensor materials. ${ }^{9,10}$ Furthermore, as they present high physico-chemical stability and benefit of low cost production processes, they are considered as ideal candidates for many sensing applications. ${ }^{9-13}$ Due to its high charge carrier transport properties and excellent physical properties, zinc oxide ( $\mathrm{ZnO}$ ) became a material of choice for gas detection. ${ }^{14-16} \mathrm{ZnO}$ nanomaterials and in particular nanowires (NWs) have gained a particular attention for gas sensing. ${ }^{13,17,18}$ However, such sensors present relatively low performance, hindering their practical use, and research efforts are still required to improve the gas sensing response selectivity and intensity. One strategy for the enhancement of sensing performance is the formation of heterojunctions between different materials. In fact, when intimate contact between various semiconductors occur, Schottcky barriers are formed, and the modulation of height of the barrier in the presence of the target gas will change the resistance of the gas sensor device. ${ }^{17}$

Due to the affinity of palladium (Pd) material with hydrogen gas, it has been used for hydrogen detection since the 1970 's. ${ }^{19} \mathrm{Pd}$ is a well-known catalyst possessing $\mathrm{H}_{2}$ bond breaking abilities. Besides, under high concentrations of hydrogen gas, $\mathrm{Pd}$ may be converted to $\mathrm{PdH}_{\mathrm{x}}$, resulting in a lattice expansion and a modification of the electrical resistance, which can be used for hydrogen gas sensing as well. ${ }^{20}$ Through a spillover effect, $\mathrm{Pd}$ can easily enhance the response of $\mathrm{ZnO} N W s$ gas sensors. Therefore, the use of Pd nanoparticles (NPs) at the surface of $\mathrm{ZnO} N W s$ has been successfully applied for hydrogen detection and it has been shown as a good strategy to improve the sensing performance. ${ }^{21,22}$ In order to enhance the catalytic activity of such NPs, their size should be optimal, but the material they are supported on plays an important role as well. ${ }^{23}$ In fact, while most of NPs are typically supported on carbon or high melting point oxides, it has been shown that emerging catalyst supports such as boron nitride (BN) based materials are promising for heterogeneous catalysis as well, as Pd NPs supported on BN allowed for the enhanced performance of different catalytic reactions. ${ }^{24-32}$ In addition, recent attention has been reported for the potential applications of BN in gas sorption, especially in case of hydrogen. ${ }^{33,34}$ The use of nitrides for the fabrication of efficient hydrogen sensors has been recently reported as well, and the nitride layer inserted in metal/semiconductor interfaces was found to cause dramatic changes in hydrogen sensing performance, implying that chemical selectivity to hydrogen could be achieved. ${ }^{35}$ Therefore, the integration of $\mathrm{BN}$ and $\mathrm{Pd}$ 
nanomaterials on ZnO NWs appears very promising and should lead to enhanced hydrogen responses.

A novel promising strategy for the direct growth of both thin films and NPs with controllable dimensions at the (sub)nanometer scale is atomic layer deposition (ALD), a vapor phase technology. ALD is based on the sequential use of self-limiting chemical reactions, enabling the synthesis of inorganic nanomaterials such as oxides, ${ }^{36,37}$ nitrides ${ }^{38-40}$ and metals, $, 41,42$ with a subnanometer level control of the thickness. ${ }^{43,44}$ An ALD cycle consists of alternate pulses of precursor and co-reactant gases, separated by purge or pumping steps. ${ }^{43,45}$ The main benefits of the ALD route are the atomic-level thickness control, the excellent uniformity and the conformality over the substrate surface, making it a technique of choice for the coating of $3 \mathrm{D}$ materials such as nanowires. ${ }^{43,44,46-48}$ These key benefits enabled this technique to become an important technology for the deposition of thin films for a myriad of applications, especially microelectronics, ${ }^{49,50}$ but also biosensing, ${ }^{51}$ catalysis ${ }^{52,53}$ and membranes. ${ }^{54}$

The preparation of BN materials by ALD is challenging, but several successful processes have been reported recently, enabling for the deposition of high quality BN films with high uniformity and conformality. ${ }^{39,55-62}$ Due to the difference of surface energies between the metal and the substrate surface, ${ }^{23}$ ALD of metals such as Pd typically initiates with the formation of NPs at the substrate surface, which grow with the increase of the number of cycles before forming a continuous film..$^{53,63}$ This nucleation stage can therefore be advantageously applied for the synthesis of highly dispersed metallic NPs on high surface area supports. Therefore, in the last decade, ALD has become a promising new route for the synthesis of metallic NPs. ${ }^{53,64-70}$ Pd NPs prepared by ALD have been widely studied, and the NPs have been grown on oxides, ${ }^{42,71-74}$ nitrides $^{32}$ and carbon supports. ${ }^{52,75,76}$ Furthermore, the catalytic activity of Pd NPs synthesized by ALD has been assessed for important chemical reactions such as methanol, 71 ethanol, ${ }^{73}$ isopropanol, ${ }^{76}$ glycerol, ${ }^{52}$ and glucose oxidation..$^{77}$

Recently, our research team has reported an innovative strategy to improve the selectivity of integrated gas sensing devices by overcoating metal oxide nanowires (NWs) with Pd NPs and a thin uniform metal organic framework (MOF) permselective nanomembrane offering molecular sieving properties. ${ }^{22}$ Three steps were required for the synthesis of these sensor devices. Despite the good performance measured, other synthesis methods are still desired to ease the upscaling of the process and to enhance both the gas sensing devices response and selectivity in the presence of interfering reducing gases.

In this work, we present a novel and easy route for the preparation of sensing devices with both enhanced hydrogen sensitivity and selectivity. The sensors considered in this work are based on $\mathrm{ZnO}$ NWs coated with a thin layer of BN decorated with Pd NPs. The fabrication of such sensing devices uses only two consecutive steps: i) coating of a miniaturized sensor with a forest of $\mathrm{ZnO} N W s$ using a vapor growth route, ii) deposition of a thin BN film and Pd NPs by ALD, also in gas phase. The prepared Pd NPs/BN decorated ZnO NWs were then characterized in terms of their microstructure and composition. Finally, the performance of the sensors for hydrogen detection in the presence of interfering gases has been studied as well. The sensitivity and selectivity of the novel sensor device were then confronted to the ones obtained with sensing devices based on bare ZnO NWs and only Pd NPs decorated ZnO NWs, which were also fabricated and tested for comparison purposes.

\section{Experimental section}

\subsection{Fabrication of the sensor device structure and growth of $\mathrm{ZnO}$ NWs}

The sensing device considered in this work has been prepared using conventional microelectronic fabrication routes in order to allow its potential future integration. First, an interdigital electrode (IDE) has been fabricated on $\mathrm{SiO}_{2}$ (200 nm thick)-grown Si (100) substrates using a lithography process. The IDE consisted of three sputtered layers: Au $(3 \mathrm{~nm}), \mathrm{Pt}(100 \mathrm{~nm})$ and Ti $(50 \mathrm{~nm})$. As already reported in our previous work, ${ }^{78}$ the $\mathrm{Au}$ was employed for its catalytic properties, the Pt layer served as an electrical pathway and the Ti layer was used to obtain the adhesion between the Si substrate and the Pt layer. The resulting sensor samples consist of 20 electrode pads.

Finally, the sensor device was coated with three-dimensional interwoven mat of interconnected ZnO NWs. The preparation of ZnO NWs was performed using a vapor-liquid-solid (VLS) growth method. ZnO NWs were grown selectively on the Au layer already deposited on the substrate, which fulfilled a catalytic role. The growth of $\mathrm{ZnO} N W s$ was carried out in a furnace with highly pure metallic $\mathrm{Zn}$ powders and constant $\mathrm{Ar}$ and $\mathrm{O}_{2}$ flows at $950^{\circ} \mathrm{C}$ for $1 \mathrm{~h}$.

\subsection{Atomic layer deposition}

All the ALD depositions have been carried out in a low-pressure hotwall (home-built) ALD reactor. ALD of BN was based on the sequential introduction of $\mathrm{BBr}_{3}$ (Sigma Adrich) and ammonia gas in the reactor. Boron tribromide $\left(\mathrm{BBr}_{3}\right)$ precursor was purchased from Sigma Aldrich and used as received. The precursor and co-reactant lines were directly connected to the reactor through gate valves and heated at $110^{\circ} \mathrm{C}$ to avoid condensation. The deposition chamber was set at a temperature of $750^{\circ} \mathrm{C}$. If not stated otherwise, the typical ALD cycle consisted of $0.1 \mathrm{~s}$ pulse of $\mathrm{BBr}_{3}, 5 \mathrm{~s}$ exposure, and $15 \mathrm{~s}$ purge, followed by a $3 \mathrm{~s}$ pulse of $\mathrm{NH}_{3}, 5 \mathrm{~s}$ exposure and 15 $s$ purge with Argon. If not mentioned otherwise, 40 cycles were used to prepare a thin BN film at the surface of the nanowires.

ALD of Pd was based on Pd(hfac) 2 (Sigma Adrich) and formalin. The highly dispersed Pd NPs were synthesized by applying 100 ALD cycles in a low-pressure hot-wall (home-built) ALD reactor. The typical Pd ALD cycle consisted of $5 \mathrm{~s}$ pulse of $\mathrm{Pd}(\mathrm{hfac})_{2}, 15 \mathrm{~s}$ exposure, and $10 \mathrm{~s}$ purge, followed by a $1 \mathrm{~s}$ pulse of formalin, $15 \mathrm{~s}$ exposure and $60 \mathrm{~s}$ purge with Ar. The bubbler containing the $\mathrm{Pd}(\mathrm{hfac})_{2}$ precursor was heated at $70^{\circ} \mathrm{C}$ and the formalin container was kept at room temperature. The deposition chamber was set at a temperature of $220^{\circ} \mathrm{C}$, and the lines in the ALD system were heated at $100{ }^{\circ} \mathrm{C}$ to avoid any condensation.

\subsection{Physico-chemical characterizations}

High Resolution Scanning Electron Microscopy (FESEM, Hitachi S4800) has been used for sample imaging. Transmission Electron Microscopy (TEM) (JEOL ARM 200F high-resolution transmission electron microscope $(200 \mathrm{kV})$ ) equipped with an Energy-dispersive $\mathrm{X}$-ray Spectroscopy (EDX) analyzer was employed for morphological 
and composition characterization. Electron Energy Loss Spectroscopy (EELS) was used to confirm the composition of samples. EELS analysis were performed using a Gatan's Quantum GIF EELS spectrometer installed in the same JEOL microscope. Spectroscopic ellipsometry (Semilab GESLAB) measurements have been used to verify the thickness of the film grown. To observe the NWs, sample sections were cut using a focused ion beam milling and imaging system (FIB, JEOL JIB-4000). In order to prepare separated NWs for TEM, the samples were tilted $\left(60^{\circ}\right)$ and then FIB milling lines were carried out to cut NWs out of the surface. Finally, the samples were dipped in ethanol and ultrasonicated for 10 minutes. $15 \mu \mathrm{l}$ of the obtained solution were dropped onto a $\mathrm{Cu}$ grid to finally achieve the TEM imaging. The chemical composition of the grown material has been determined by both EDX analysis (Zeiss EVO HD-15) and X-ray Photoelectron Spectroscopy (XPS) (ESCALAB 250 Thermal Electron) with Al-Ka (1486.6 eV), where the binding energies were calibrated using carbon (C $1 \mathrm{~s}=284.4 \mathrm{eV})$.

\subsection{Sensing measurements}

The gas sensing performances of bare $\mathrm{ZnO} N W s, \mathrm{BN} / \mathrm{ZnO} \mathrm{NWs}$, $\mathrm{Pd} / \mathrm{ZnO} \mathrm{NWs}$ and $\mathrm{Pd} / \mathrm{BN} / \mathrm{ZnO} \mathrm{NWs}$ sensors were studied by exposing the sensors to different gases at various temperatures using a specifically designed sensing system apparatus. The concentration of target gas in the sensing measurement chamber was precisely controlled by adjusting the mixing ratio between the target gas and dry air using accurate mass flow controllers (total flow rate $=500 \mathrm{sccm}$ ). During the sensing measurement process, the change in the electrical resistance $(R)$ of the sensor when the target gas was introduced and stopped was continuously monitored and recorded by a computer. The gas sensing properties were assessed through the response value of the sensor, which was defined as $R=R_{a} / R_{g}$, where $R_{a}$ and $R_{g}$ are the resistances of the sensor in air and in the presence of the target gas, respectively. The response and recovery times were defined as the time to reach $90 \%$ of the final resistance after exposure to the target gas and the time to recover $90 \%$ of the initial resistance of the sensor after removing the target gas, respectively. ${ }^{14}$

\section{Results and discussion}

\subsection{Synthesis and microstructure of Pd NPs/BN/ZnO NWs based sensors}

As gas sensing devices based on semiconductor metal oxides are typically integrated in miniaturized packages with other siliconbased elements, the sensors presented in this work have been fabricated using conventional microelectronic manufacturing routes
(CVD derived techniques). The sensing device architecture can be seen in the SEM image displayed in Figure 1a.
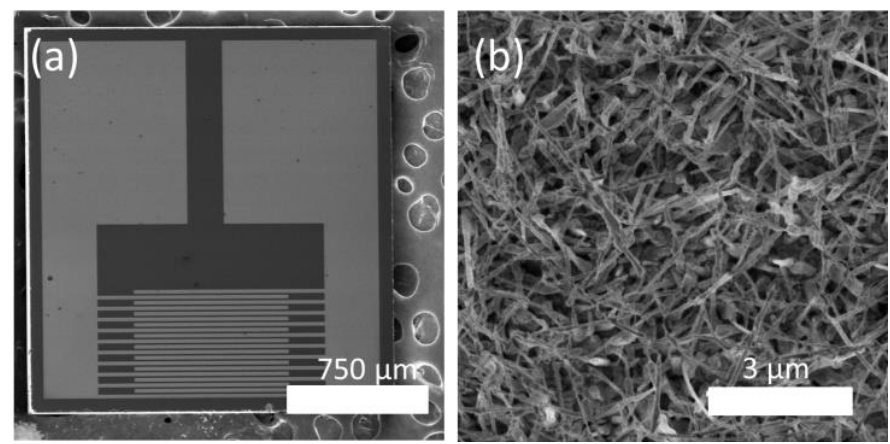

Figure 1: Top view FESEM images of (a) the sensing device and (b) network of ZnO NWs on the surface of substrate.

As detailed in the experimental part, the preparation of the novel gas sensing device (Pd NPs/BN/ZnO NWs) involves two key steps: i) Growing a network of ZnO NWs on the sensor support surface; ii) Decorating the NWs with a BN layer and Pd NPs by ALD.

First, a VLS route at $950^{\circ} \mathrm{C}$ has been employed to grow a forest of ZnO NWs. Briefly; the nanowires are grown by a liquid metal-alloy droplet-catalyzed chemical vapor deposition (CVD) process, which takes place in a vacuum deposition system. As seen in Figure $1 \mathrm{~b}$, the resulting NWs present a diameter of around $100 \mathrm{~nm}$ and are well interconnected all over the surface. The microstructure of the $\mathrm{ZnO}$ NWs has been studied in the past using grazing incidence XRD, and the NWs were found to be highly crystalline. ${ }^{22}$ Next, ALD of BN has been applied to coat these $\mathrm{ZnO} N W s$ with a conformal and thin film of BN, using 40 cycles of ALD. Each ALD cycle consisted of sequential exposures of boron tribromide $\left(\mathrm{BBr}_{3}\right)$ and $\mathrm{NH}_{3}$ gas, separated by purge steps of $\mathrm{Ar}$ at a temperature of $750^{\circ} \mathrm{C}$. This process leads to a saturated and steady-state ALD growth per cycle (GPC) of $\sim 0.8 \AA$ and no visible nucleation delay. The constant GPC of the ALD process allows for a precise control over the thickness, ${ }^{61}$ and spectroscopic ellipsometry measurements have been used to verify the thickness of the film grown on $\mathrm{Si}$ substrates in parallel. ${ }^{79,80}$ Finally, 200 cycles of ALD of Pd have been carried out in order to obtain the dispersed Pd NPs all over the surface of the NWs. The ALD of Pd was based on sequential pulses of $\mathrm{Pd}(\mathrm{hfac})_{2}$ precursor and formalin as coreactant at $220^{\circ} \mathrm{C}$. More details on the ALD processes are given in the Experimental section and can be found elsewhere. ${ }^{39,52,81-83}$

After ALD of BN and Palladium were performed on the ZnO NWs samples, TEM imaging has been employed to characterize the resulting nanomaterials. Figure $2 a$ and $2 b$ presents TEM images of the $\mathrm{ZnO}$ NWs coated with a thin layer of $\mathrm{BN}$, and Figures $2 \mathrm{c}$ and $2 \mathrm{~d}$ shows the final Pd NPs/BN/ZnO NWs nanomaterials forming the core of the novel gas sensing device. 

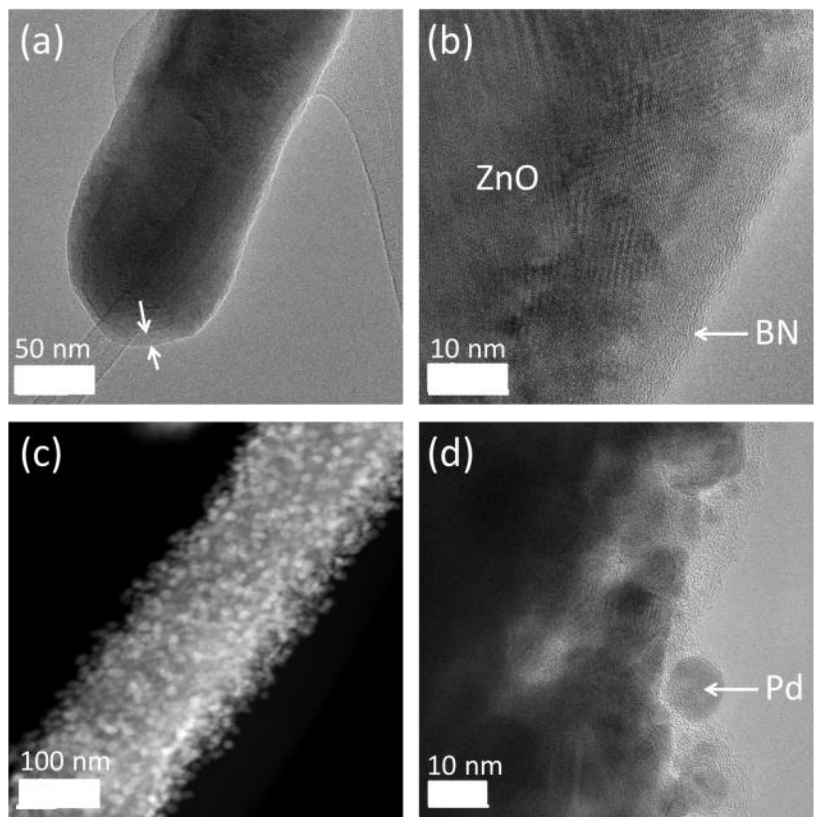

Figure 2. TEM images of $(a, b) B N / Z n O N W s$ and $(c, d)$ the $P d$ NPs/BN/ZnO NWs. In (a) and (b), the arrows indicate the BN layer. In (d), a Pd NP is designated.

From the TEM images shown in Figures $2 a, 2 b$ and $2 d$, it can be seen that the NWs are coated with a thin layer of BN. The thickness of the layer is estimated to $5 \pm 2 \mathrm{~nm}$, which is slightly higher than expected from the GPC of the BN ALD process developed on $\mathrm{Si}$. It is possible that the surface chemistry and the nanostructuration of the $\mathrm{ZnO}$ surface allows for a slightly faster deposition rate (as compared to $\mathrm{Si}$ ). The presence of Pd NPs was revealed by the strong contrast difference between the ZnO NWs and the metallic NPs during TEM observation. Indeed, highly dispersed Pd NPs at the surface of the NWs have been obtained and can be observed in Figures $2 \mathrm{c}$ and $2 \mathrm{~d}$. The NPs present a diameter of around $10 \mathrm{~nm}$ and are uniformly dispersed over the whole surface of the NWs.

To confirm the composition of the nanomaterials obtained, the use of the EELS and of the EDX detector in mapping analysis were used. As shown in Figure 3, the EELS and EDX data reveal both a uniform distribution of boron at the surface of the NW, and the presence of well dispersed Pd NPs covering homogeneously the NWs surface has been confirmed as well. The $\mathrm{Zn}$ and oxygen elements were also seen, as $\mathrm{ZnO}$ forms the core of the NWs. The thin BN film was challenging to characterize using EELS and EDX, and only a small amount of $B$ at the surface could actually be detected using EELS. However, the presence of $\mathrm{N}$ was not detected using this technique and we thus carried out XPS measurements in order to further confirm the nature of the BN layer.
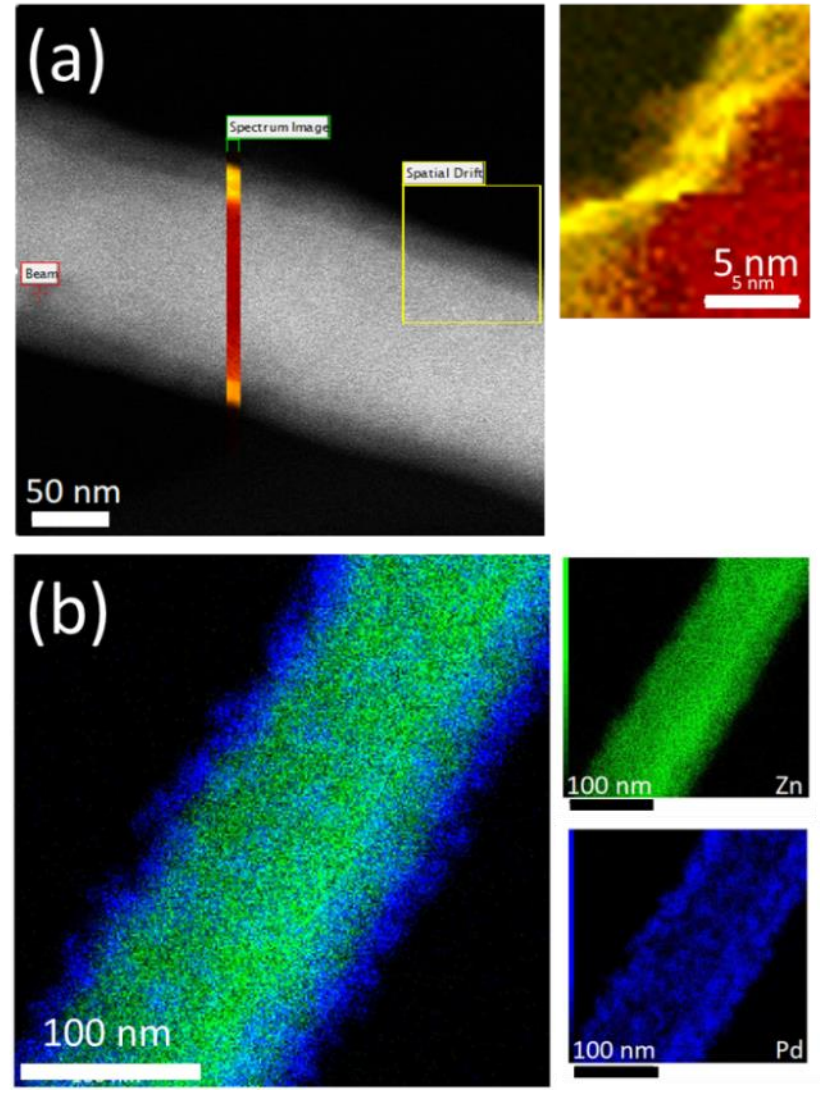

Figure 3. (a) EELS result of the Pd NPs/BN/ZnO NWs sample, where the red and yellow colors correspond to the oxygen and the boron elements, respectively. (b) EDX mapping of the $\mathrm{Pd} \mathrm{NPs} / \mathrm{BN} / \mathrm{ZnO}$ NWs. The Pd element is well detected all over the surface of the NW.

Nitrogen has been successfully detected by XPS (Figure S1, Supplementary Information), as well as the other elements expected. The binding energy of $\mathrm{N} 1 \mathrm{~s}$ was found at $398.5 \mathrm{eV}$. As anticipated, the XPS survey (Figure S2, Supplementary Information) confirmed the presence of zinc and oxygen elements, and the binding energies of $\mathrm{O} 1 \mathrm{~s}$ and $\mathrm{Zn} 2 \mathrm{p}_{3}$ were found at 532.2 and 1022.5 $\mathrm{eV}$, respectively. Metallic Pd was detected as well, as shown in the $\mathrm{Pd} 3 \mathrm{~d}$ scan presenting the deconvoluted peaks of $\mathrm{Pd} 3 \mathrm{~d}_{3}$ and $\mathrm{Pd} 3 \mathrm{~d}_{5}$ (Figure S3, Supplementary Information).

\subsection{Sensing measurements}

The sensing device response magnitude and its selectivity are key parameters in metal oxide-based gas sensors, and low values strongly limit their practical application. The $\mathrm{Pd} / \mathrm{BN} / \mathrm{ZnO} \mathrm{NWs}$ gas sensors fabricated in this work were first tested for hydrogen detection at different temperatures.

For comparison purposes, the data were confronted to the performance obtained for other ZnO NWs-based gas sensors, namely bare $\mathrm{ZnO} N W s, \mathrm{Pd} N \mathrm{Ns}$ decorated $\mathrm{ZnO} \mathrm{NWs}$ (Pd/ZnO NWs), and $\mathrm{ZnO} N W s$ coated with a thin $\mathrm{BN}$ film (Pd/BN/ZnO NWs). It should be noted that the $\mathrm{BN}$ and Pd ALD processes for these 
sensors were carried out in parallel to the ALD process used for the synthesis of novel Pd/BN/ZnO NWs gas sensor.

Figure S4 (Supplementary Information) shows the dynamic resistance curves of bare $\mathrm{ZnO} N W s$ to $50 \mathrm{ppm} \mathrm{H}_{2}$ gas at the temperature ranges of 100 to $300^{\circ} \mathrm{C}$. As expected, due to the presence of $\mathrm{Zn}$ vacancies, the sensor shows an $\mathrm{n}$-type behavior. The bare $\mathrm{ZnO} N W s$ gas sensor showed its maximum response at $300^{\circ} \mathrm{C}$ and, accordingly, the selectivity tests were also performed at this temperature. The selectivity or cross-sensitivity corresponds to a higher sensor response to a target gas in the presence of other interfering gases. In fact, a gas sensor may be sensitive not only to the targeting gas but also to the interfering gases. Figure S5 (Supplementary Information) shows the dynamic resistance curves of gas sensor towards 10, 30 and $50 \mathrm{ppm}$ of different gases at $300^{\circ} \mathrm{C}$, where not only its response to all gases is low, but also its selectivity towards $\mathrm{H}_{2}$ is poor. Once coated with the Pd NPs, as shown in Figure S6 (Supplementary Information), the dynamic resistance curves of $\mathrm{Pd} / \mathrm{ZnO} \mathrm{NWs}$ towards 10,30 and $50 \mathrm{ppm} \mathrm{H}_{2}$ gas at different temperatures ranging from 25 to $300^{\circ} \mathrm{C}$ were obtained, and the maximum response to $\mathrm{H}_{2}$ gas was observed at $200^{\circ} \mathrm{C}$. Figure $\mathrm{S} 7$ reveals the dynamic resistance curves of $\mathrm{Pd} / \mathrm{ZnO} \mathrm{NWs}$ gas sensor towards 10,30 and $50 \mathrm{ppm}$ different gases at this temperature. Even though the response to different gases was enhanced relatively to bare $\mathrm{ZnO}$ NWs gas sensor, the selectivity was still weak. Figure S8a presents the dynamic responses of BN/ZnO NWs gas sensor towards different concentrations of hydrogen and Fig. S9b shows the corresponding response versus operating temperature, where the maximum response was obtained at a temperature of $250^{\circ} \mathrm{C}$ for all concentrations of hydrogen gas. Figure S9a shows dynamic resistance plots of $\mathrm{BN} / \mathrm{ZnO} \mathrm{NWs}$ gas sensor towards different interfering gases at $200^{\circ} \mathrm{C}$ and corresponding calibration curves are shown in Figure S9b where the response increased with gas concentration. Also, the highest response was obtained for hydrogen gas alone but a poor selectivity hindered the overall performance of this sensor. Finally, the dynamic resistance curves of $\mathrm{Pd} / \mathrm{BN} / \mathrm{ZnO} \mathrm{NWs}$ gas sensor to different concentrations of hydrogen gas, at various temperatures from 25 to $300^{\circ} \mathrm{C}$ were measured, as depicted in Figure S10. The gas sensor showed its highest response at $200^{\circ} \mathrm{C}$, and the selectivity tests at this temperature are presented in Figure S11a (Supplementary Information), whereas the corresponding calibration curves are given in Figure S11b. These results clearly demonstrate the superior selectivity of $\mathrm{Pd} / \mathrm{BN} / \mathrm{ZnO} \mathrm{NWs}$ to hydrogen gas relatively to the other tested gas sensors.

To have a better insight and a clearer view of the results obtained, the behavior of these different $\mathrm{ZnO} \mathrm{NWs}$-based gas sensors to 50 ppm hydrogen gas at various temperatures were summarized.

As shown in the Figure 4 presenting these results, only the bare $\mathrm{ZnO}$ NWs gas sensor shows its optimal sensing temperature at $300^{\circ} \mathrm{C}$ whereas the $\mathrm{Pd} / \mathrm{BN} / \mathrm{ZnO} \mathrm{NWs}$ gas sensor presented a lower optimal sensing temperature at $200^{\circ} \mathrm{C}$. This demonstrates the promising effects of both $\mathrm{Pd}$ and $\mathrm{BN}$ for the decrease of the sensing temperature, which is obviously desirable for the practical application. Also, among the different gas sensors, Pd/BN/ZnO NWs shows the highest response to hydrogen gas, confirming the synergetic effects of $\mathrm{Pd}$ and $\mathrm{BN}$ for the sensing enhancement of $\mathrm{ZnO}$ NWs. The inset in Figure 4 shows normalized dynamic resistance curves of different gas sensors to $50 \mathrm{ppm} \mathrm{H}_{2}$ gas at $200^{\circ} \mathrm{C}$, where the resistances of all sensors are plotted back to their original values, demonstrating the good reversibility of these sensors.

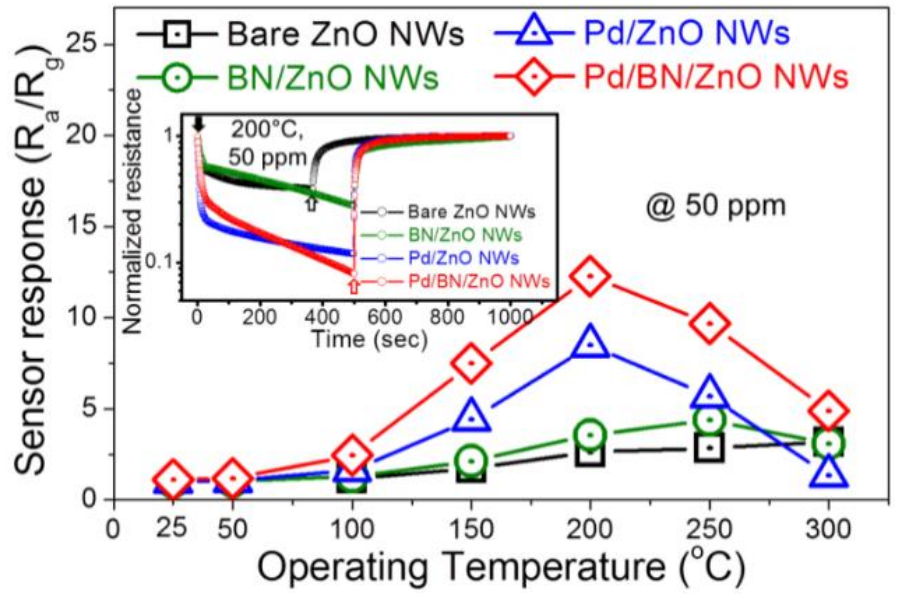

Figure 4. Response versus operating temperature for the different $\mathrm{ZnO} \mathrm{NWs}$-based gas sensors studied in this work. The inset compares the normalized resistance curves of different gas sensors at $200^{\circ} \mathrm{C}$ to $50 \mathrm{ppm}$ hydrogen gas.

Figure 5 presents the selectivity histograms obtained using these different $\mathrm{ZnO} \mathrm{NWs}$-based gas sensors towards various gases, namely $\mathrm{C}_{6} \mathrm{H}_{6}, \mathrm{C}_{7} \mathrm{H}_{8}, \mathrm{C}_{2} \mathrm{H}_{5} \mathrm{OH}$ and $\mathrm{CH}_{3} \mathrm{COCH}_{3}$. Overall, it can be seen that the sensor response towards different gases is in the following order; bare $\mathrm{ZnO} \mathrm{NWs}<\mathrm{BN} / \mathrm{ZnO} \mathrm{NWs}<\mathrm{Pd} / \mathrm{ZnO} \mathrm{NWs}<\mathrm{Pd} / \mathrm{BN} / \mathrm{ZnO}$ $\mathrm{NWs}$. For example, for $50 \mathrm{ppm}$ hydrogen gas at $200^{\circ} \mathrm{C}$, the responses of the mentioned gas sensors are 2.63 $( \pm 0.13)$, $3.55( \pm 0.18), 8.48( \pm 0.42)$ and $12.28( \pm 0.61)$, respectively. The highest sensor response of $12.28( \pm 0.61)\left(R_{a} / R_{g}\right)$ has been obtained for the new $\mathrm{Pd} / \mathrm{BN} / \mathrm{ZnO} \mathrm{NWs}$ design at $200^{\circ} \mathrm{C}$, clearly outperforming the other $\mathrm{ZnO}$ NWs-based gas sensors. Table S1 (Supplementary Information) compares the hydrogen gas sensing properties of the present sensor with those reported in the literature. As seen in this Table S1, the new $\mathrm{Pd} / \mathrm{BN} / \mathrm{ZnO}$ gas sensor design enables a high response at relatively low operating temperature, as only $\mathrm{WO}_{3}-\mathrm{ZnO}$ NWs based sensors reached a similar result at $200^{\circ} \mathrm{C}$, but for a gas concentration two orders of magnitude higher. Since the $\mathrm{Pd} / \mathrm{BN} / \mathrm{ZnO} \mathrm{NWs}$ gas sensor showed the best sensing performance, it was selected for further studies.

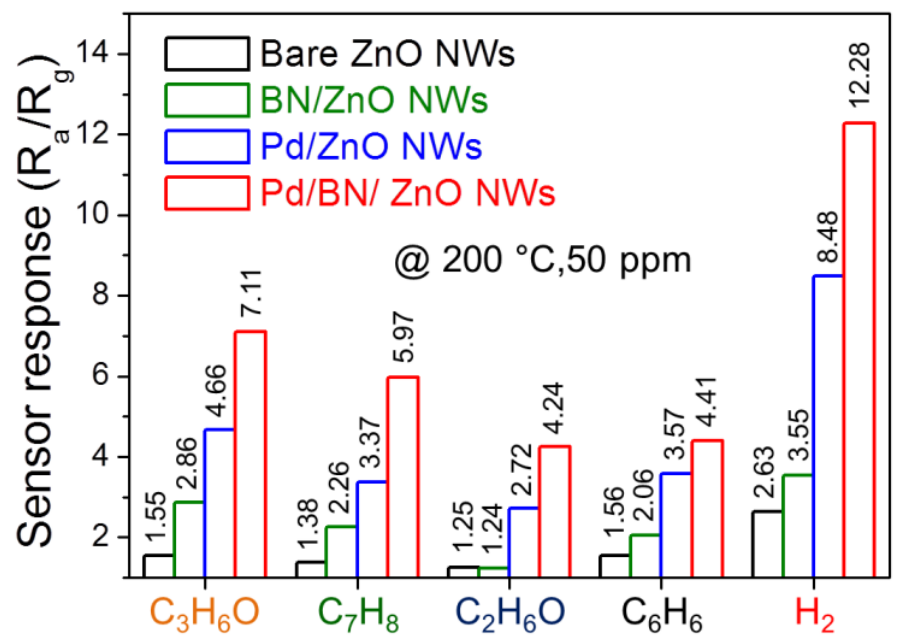


Figure 5. Comparison between the selectivity histograms of different $\mathrm{ZnO} \mathrm{NWs}$-based gas sensors to $50 \mathrm{ppm}$ different gases at $200^{\circ} \mathrm{C}$.

To further investigate the selectivity of $\mathrm{Pd} / \mathrm{BN} / \mathrm{ZnO}$ NWs gas sensor, it was exposed to a mixed gas of $\mathrm{C}_{6} \mathrm{H}_{6}+\mathrm{H}_{2}$, and the dynamic resistance curve for different concentrations of mixed gas measured is shown in Figure 6a. Figure 6b depicts the comparison of the response of this gas sensor to $\mathrm{H}_{2}$ gas, mixed gas and $\mathrm{C}_{6} \mathrm{H}_{6}$ gas. As shown in this figure, the sensor has a higher response to mixed gas relatively to pure $\mathrm{C}_{6} \mathrm{H}_{6}$ gas, demonstrating its good selectivity even in a mixture of gases. The reasons behind the better selectivity of $\mathrm{Pd} / \mathrm{BN} / \mathrm{ZnO} \mathrm{NW}$ gas sensor obtained will be discussed in the Section 3.3 (Sensing mechanisms).
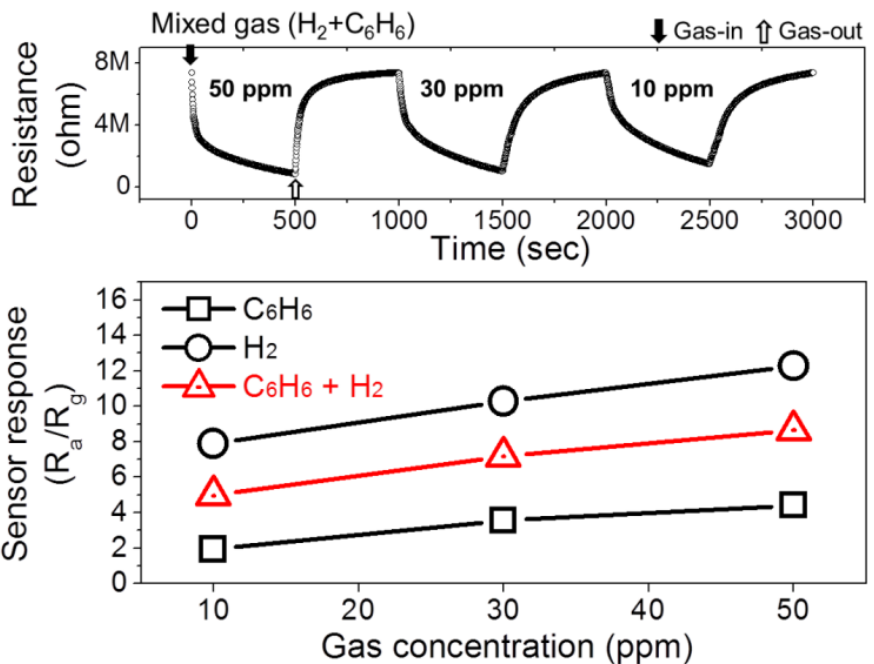

Figure 6. Dynamic resistance curve of $\mathrm{Pd} / \mathrm{BN} / \mathrm{ZnO} \mathrm{NWs}$ gas sensor towards 10,30 and $50 \mathrm{ppm}$ mixed gas $\left(\mathrm{H}_{2}+\mathrm{C}_{6} \mathrm{H}_{6}\right)$ and comparison between the responses of gas sensor towards $\mathrm{C}_{6} \mathrm{H}_{6}, \mathrm{H}_{2}$ and mixed gas $\left(\mathrm{H}_{2}+\mathrm{C}_{6} \mathrm{H}_{6}\right)$.

In order to evaluate the limits of the novel device, further testings have been carried out at lower gas concentrations. Figure 7a shows the dynamic resistance curves of this sensor to extremely low concentrations of hydrogen gas $(0.1-10 \mathrm{ppm})$ at $200^{\circ} \mathrm{C}$, whereas Figure $7 \mathrm{~b}$ depicts the response versus gas concentration obtained. It has been found that the hydrogen could be detected for concentrations as low as $0.5 \mathrm{ppm}$. The response values obtained for $0.5,1$ and 10 ppm hydrogen concentrations are 1.34, 2.17 and 7.95 respectively.

For practical sensing applications, the humidity present in the environment is also a concern. Hence, initial studies on the effect of humidity on the response of this gas sensor have been carried out as well. For this purpose, the dynamic resistance curves of $\mathrm{Pd} / \mathrm{BN} / \mathrm{ZnO} \mathrm{NWs}$ gas sensor towards $50 \mathrm{ppm} \mathrm{H}_{2}$ gas in the presence of 0 and $60 \%$ relative humidity $(\mathrm{RH})$ have been measured at $200^{\circ} \mathrm{C}$. As shown in Figure $7 c$, the response was only barely affected by the presence of humidity. For example, as shown in Figure $7 d$, for the first cycle, the response was decreased from 12.28 to 11.41 with increasing of RH to $60 \%$. However, the dynamic of the gas sensor was slightly decreased in the presence of humidity, as the response time was increased from 160 to $240 \mathrm{~s}$, and the recovery time was increased from 90 to $150 \mathrm{~s}$, upon increase of $\mathrm{RH}$ to $60 \%$ (Figure 7e).

(a)

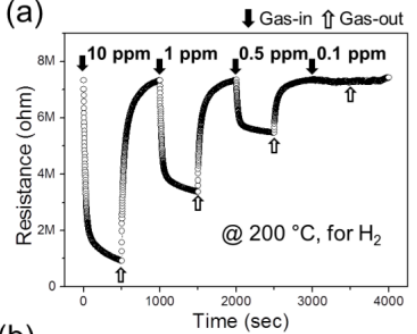

(c) @ $200^{\circ} \mathrm{C}$, for $50 \mathrm{ppm} \mathrm{H}$

(b)
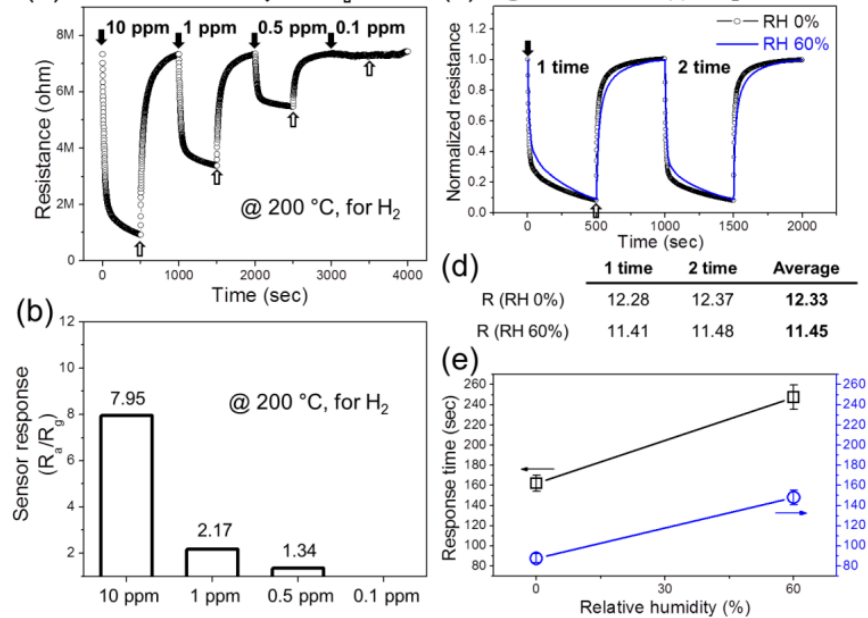

(e)

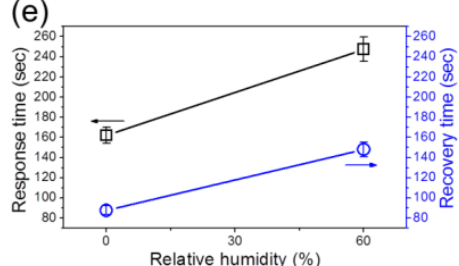

Figure 7. (a) Dynamic resistance curves of $\mathrm{Pd} / \mathrm{BN} / \mathrm{ZnO} \mathrm{NWs}$ gas sensor towards low concentrations of hydrogen gas at $200^{\circ} \mathrm{C}$. (b) Response versus $\mathrm{H}_{2}$ gas concentration. (c) Dynamic resistance curves of $\mathrm{Pd} / \mathrm{BN} / \mathrm{ZnO} \mathrm{NWs}$ gas sensor towards $50 \mathrm{ppm} \mathrm{H}_{2}$ gas at $200^{\circ} \mathrm{C}$, in the presence of 0 and $60 \% \mathrm{RH}$. (d) Response values in the presence of 0 and $60 \% \mathrm{RH}$ for the first time, the second time and average (e) Response and recovery times versus $\mathrm{RH} \%$.

\subsection{Sensing mechanisms}

The first hypothesis explaining the high performance obtained using this novel $\mathrm{Pd} / \mathrm{BN} / \mathrm{ZnO} \mathrm{NWs}$ design could be the modulation of height of the $\mathrm{ZnO}$ semiconductor barrier, which modifies the resistance of the gas sensor device. It is in fact well-known that the sensing mechanism of resistive-based gas sensors is due to the variations of the resistance in the presence of target gas. Accordingly, any factor leading to the resistance modulation of the gas sensor can contribute to the sensing enhancement. When the gas sensor is in air, oxygen molecules are adsorbed on its surface, leading to the appearance of an electron depletion layer at the surface of the sensor. At $200^{\circ} \mathrm{C}$, which was the optimal sensing temperature measured, the dominant oxygen species are $0^{-}$. Upon exposure of the sensor to hydrogen gas, the $\mathrm{O}^{-}$species react with hydrogen gas as follows: $\mathrm{H}_{2}+\mathrm{O}^{-} \rightarrow \mathrm{H}_{2} \mathrm{O}+\mathrm{e}^{-}$. Thus, the width of electron depletion layer will be decreased due to release of electrons to the surface of the gas sensor, and a sensing signal will be obtained. However, the response measured using pristine $\mathrm{ZnO}$ gas sensors is not remarkable due to the limitation of the resistance modulation sources. In contrast, in a structure such as $\mathrm{Pd} / \mathrm{BN} / \mathrm{ZnO}$, more sources of resistance modulation exist. First of all, it is reasonable to consider the roles of $\mathrm{BN}$ and $\mathrm{Pd}$ on the sensing behavior of $\mathrm{ZnO} N W s$. In $\mathrm{BN}$ coated $\mathrm{ZnO}$ as shown in Figure 8a, since a thin $(5 \pm 2 \mathrm{~nm}) \mathrm{BN}$ film is coated around the $\mathrm{ZnO} N W s$, due to the work function difference between $\mathrm{ZnO}$ and $\mathrm{BN}, 84,85$ in intimate contact between $\mathrm{ZnO}$ and $\mathrm{BN}$ electrons from $\mathrm{ZnO}$ are transferred to $\mathrm{BN}$ and Schottcky barriers (height of $5.52 \mathrm{eV}$ ) will be formed on the interfaces between $\mathrm{ZnO}$ and $\mathrm{BN}$ (Figure S12a), which can expand the electron depletion layer relative to pristine $\mathrm{ZnO} N W s$. Upon 
exposure of gas sensor to hydrogen gas and release of electrons to the surface of $\mathrm{ZnO} \mathrm{NWs}$, the height of this barrier will be significantly decreased, leading to a greater resistance modulation and a more sensing response. In addition, due to the fact the BN layer is extremely thin, it is possible that some $\mathrm{Pd}$ and $\mathrm{ZnO}$ are in contact (Figure $8 \mathrm{~b}$ ). Again due to the work function difference between Pd and $\mathrm{ZnO}$, Schottcky barriers could be also formed at the interface between $\mathrm{Pd}$ and $\mathrm{ZnO}$. Upon exposure to hydrogen gas, the height of this barrier will be significantly decreased and this can also contribute to the resistance modulation of the gas sensor. Figure $\mathrm{S} 12 \mathrm{~b}$ schematically shows the formation of Schottcky barriers in $\mathrm{ZnO} / \mathrm{Pd}$. In Pd/BN/ZnO NWs, as shown in Figure 8c, both Pd and BN synergistically lead to enhanced gas sensing response due to significantly expanded electron depletion layer (EDL) layer of $\mathrm{ZnO}$ NWs and an initially large resistance, where the released electrons can remarkably decrease the resistance of gas sensor, leading to the enhanced sensing response.

\section{(a) $\mathrm{BN} / \mathrm{ZnO} \mathrm{NWs}$}
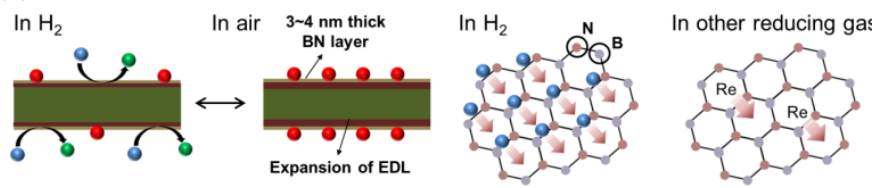

(b) $\mathrm{Pd} / \mathrm{ZnO}$ NWs
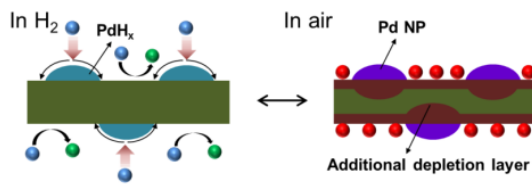

In other reducing gas

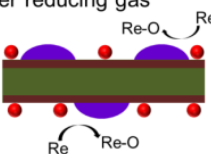

(c) $\mathrm{Pd} / \mathrm{BN} / \mathrm{ZnO} \mathrm{NWs}$

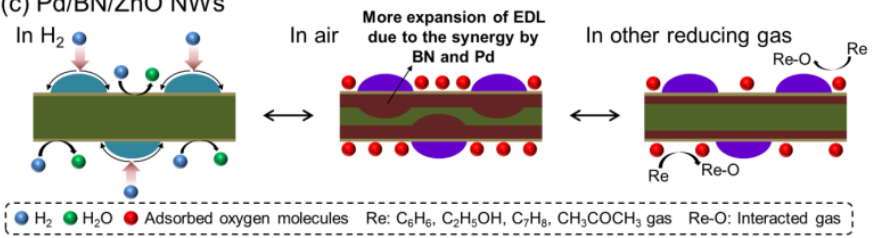

In air More expansion of EDL

reducing gas

Figure 8. Schematic representation of the sensing mechanisms for (a) pristine $\mathrm{ZnO} \mathrm{NWs}$, (b) BN/ZnO NWs and (c) Pd/BN/ZnO NWs sensors.

Obviously, the affinity of the Pd NPs with hydrogen gas plays also a crucial rule for the high sensing response to this gas. Pd can adsorb significant amount of hydrogen molecules and dissociate them, and, upon exposure to hydrogen gas. It is also likely that the metallic $\mathrm{Pd}$ will be partially converted to $\mathrm{PdH}_{\mathrm{x}}$. Due to the difference in the resistance of $\mathrm{Pd}$ and $\mathrm{PdH}_{\mathrm{x}}$, this conversion is also expected to enhance the sensitivity of the gas sensor. It has been reported that the work function of $\mathrm{PdH}_{\mathrm{x}}$ is in the range of 3.2-5.27 eV. ${ }^{86,87}$ As shown in Figure S12c and $d$, upon conversion of $P d$ to $P_{d H}$, the work function of Pd changes, which can be a source of sensor's resistance in gas sensor. In addition, due to special structure of $B N$ which is similar to graphene with small voids, ${ }^{88,89}$ it can act as a membrane and let gas molecules reach the surface of ZnO NWs. Due to very small kinetic diameter of hydrogen molecules, the nitride being permeable to hydrogen atoms and hydrogen molecules can easily pass the $\mathrm{BN}$ layer, whereas bigger molecules such as $\mathrm{C}_{6} \mathrm{H}_{6}, \mathrm{C}_{7} \mathrm{H}_{8}, \mathrm{C}_{2} \mathrm{H}_{6} \mathrm{O}$ and $\mathrm{C}_{3} \mathrm{H}_{6} \mathrm{O}$ cannot easily cross the nitride layer. This phenomenon can also increase the selectivity of the present gas sensor towards hydrogen gas. However, if a thin layer of only a few nanometers can effectively enable the transfer of hydrogen species to take place, nitrides films are only able to act as hydrogen membranes upon a certain point. As there is not a direct driving force for the hydrogen to cross the BN "membrane" layer, a thicker layer would therefore result in a lower permeation of species, and hence reduce the sensor signal and cancel the first (EDL) positive effect. Therefore, it is expected that thicker films would result in considerably lower sensing responses, and the use of ALD for the preparation of such thin and conformal films is justified.

\section{Conclusions}

In this work, we reported a novel strategy for the enhancement of both sensitivity and selectivity of metal oxidebased gas sensing devices, applied to the detection of hydrogen gas.

The sensors presented were based on ZnO NWs coated with a $5 \pm 2 \mathrm{~nm}$ BN film decorated with Pd NPs. The fabrication of such sensing devices uses only two consecutive and upscalable steps: i) growing a forest of $\mathrm{ZnO} N W$ s on top of a miniaturized sensor using VLS, a vapor growth route, ii) Conformally coating these NWs with a BN film and Pd NPs using ALD, also in gas phase. The prepared Pd NPs/BN decorated ZnO NWs were characterized in terms of physico-chemistry and their performance for hydrogen detection in the presence of interfering gases has been assessed. A very high sensor response of $12.28( \pm 0.61)\left(R_{a} / R_{g}\right)$ has been measured for the new Pd/BN/ZnO NWs designed sensor at $200^{\circ} \mathrm{C}$, and an excellent selectivity has been achieved as well for hydrogen in the presence of various gases such as $\mathrm{C}_{6} \mathrm{H}_{6}, \mathrm{C}_{7} \mathrm{H}_{8}, \mathrm{C}_{2} \mathrm{H}_{5} \mathrm{OH}$ and $\mathrm{CH}_{3} \mathrm{COCH}_{3}$. These results achieved clearly outperformed the ones obtained with other ZnO NWs based sensor devices in the literature. In addition, our experiments revealed that the hydrogen gas could be detected for concentrations as low as $0.5 \mathrm{ppm}$ using the novel sensor design, and that this sensor was only barely affected by the presence of humidity. The high performance measured using this novel Pd NPs/BN/ZnO NWs designed sensor was explained by the modulation of height of the semiconductor barrier in the presence of the hydrogen gas, which modified the resistance of the gas sensor device, increasing its response. The Pd NPs affinity with hydrogen gas was also crucial for the sensing response to this gas. Finally, the fact that these NPs are supported on BN potentially enhanced their catalytic activity, and, the nitride membrane being permeable to hydrogen, the thin BN film is also expected to play a major role in the high sensitivity and selectivity measured.

The proof-of-concept results presented in this work pave the way for the development of a new generation of highly sensitive and selective gas sensors combining innovative nanomaterials. Furthermore, the industrial scalability of the devices presented in this work is possible; as the sensors have been fabricated using CVD derived routes, which are conventional microelectronic manufacturing techniques. Thus, we believe that the data obtained will boost the development of hydrogen sensing device technologies, facilitating the hydrogen economy to ramp up. 


\section{Conflicts of interest}

There are no conflicts to declare.

\section{Acknowledgements}

The authors are grateful to Bruno Navarra (CNRS-IEM) for his technical assistance and Valérie Flaud (CNRS-ICG) for XPS measurements. This research study was supported by the French National Agency (ANR, program MeNiNA - ANR-17CE09-0049) and by the Basic Science Research Program through the National Research Foundation of Korea (NRF) funded by the Ministry of Education (2016R1A6A1A03013422).

\section{Notes and references}

M. Z. Jacobson, W. G. Colella and D. M. Golden, Science (80-. )., 2005, 308, 1901-1905.

P. E. Dodds, I. Staffell, A. D. Hawkes, F. Li, P. Grünewald, W. McDowall and P. Ekins, Int. J. Hydrogen Energy, 2015, 40, 2065-2083. S. Sharma and S. K. Ghoshal, Renew. Sustain. energy Rev., 2015, 43, 1151-1158.

N. Parkinson, Air Liquide to build $\$ 150 \mathrm{~m}$ liquid hydrogen production plant in western US, https://www.gasworld.com/air-liquide-to-build-150mhydrogen-plant-/2015979.article. Y. Hong, C. H. Kim, J. Shin, K. Y. Kim, J. S. Kim, C. S. Hwang and J. H. Lee, Sensors Actuators, B Chem., 2016, 232, 653659. devices, CRC Press, 2016

L. Yang, C. Yin, Z. Zhang, J. Zhou and H. Xu, Mater. Sci.

Y. Zhang, H. Peng, T. Zhou, L. Zhang, Y. Zhang and Y. Zhao, Sensors Actuators B Chem., 2017, 248, 71-76.

Phys. Soc., 2014, 65, 1414-1418.

H. Kheel, G.-J. Sun, J. K. Lee, A. Mirzaei, S. Choi and C. Lee, Met. Mater. Int., 2017, 23, 214-219.

Asia, 2003, 7, 63-75.

G. Korotcenkov, Mater. Sci. Eng. B, 2007, 139, 1-23.

H.-J. Kim and J.-H. Lee, Sensors Actuators B Chem., 2014, 192, 607-627.

L. Zhu and W. Zeng, Sensors Actuators A Phys.

R. Kumar, O. Al-Dossary, G. Kumar and A. Umar, NanoMicro Lett., 2015, 7, 97-120.

I. Paulowicz, V. Postica, O. Lupan, N. Wolff, S. Shree, A. Cojocaru, M. Deng, Y. K. Mishra, I. Tiginyanu and L. Kienle, Sensors Actuators B Chem., 2018, 262, 425-435.

D. R. Miller, S. A. Akbar and P. A. Morris, Sensors Actuators B Chem., 2014, 204, 250-272.

A. Katoch, S.-W. Choi, H. W. Kim and S. S. Kim, J. Hazard. Semicond. Process., 2017, 60, 16-28.
19

20

Mater., 2015, 286, 229-235.

L. Stiblert and C. Svensson, Rev. Sci. Instrum., 1975, 46, 1206-1208.

Y.-S. Shim, B. Jang, J. M. Suh, M. S. Noh, S. Kim, S. D. Han, Y. G. Song, D. H. Kim, C.-Y. Kang and H. W. Jang, Sensors Actuators B Chem., 2018, 255, 1841-1848. Y. Zhang, Q. Xiang, J. Xu, P. Xu, Q. Pan and F. Li, J. Mater. Chem., 2009, 19, 4701-4706. M. J. Weber, J.-H. Kim, J.-H. Lee, J.-Y. Kim, I. latsunskyi, E. Coy, M. Drobek, A. Julbe, M. Bechelany and S. S. Kim, ACS Appl. Mater. Interfaces, 2018, 10, 34765-34773.

C. T. Campbell, Surf. Sci. Rep., 1997, 27, 1-111.

Mater. Matters, 2013.

G. Postole, M. Caldararu, N. I. Ionescu, B. Bonnetot, A. Auroux and C. Guimon, Thermochim. Acta, 2005, 434, 150157.
N. Meyer, K. Bekaert, D. Pirson, M. Devillers and S. Hermans, Catal. Commun., 2012, 29, 170-174. J. C. S. Wu, C.-Y. Chen and S. D. Lin, Catal. Letters, 2005, 102, 223-227.

L. Gao, Q. Fu, M. Wei, Y. Zhu, Q. Liu, E. Crumlin, Z. Liu and X. Bao, ACS Catal., 2016, 6, 6814-6822.

R. Schimmenti, R. Cortese, D. Duca and M. Mavrikakis, ChemCatChem, 2017, 9, 1610-1620.

N. Meyer, M. Devillers and S. Hermans, Catal. Today, 2015, 241, 200-207.

Y. Yabe, Y. Sawama, T. Yamada, S. Nagata, Y. Monguchi and H. Sajiki, ChemCatChem, 2013, 5, 2360-2366.

M. Weber, C. Lamboux, B. Navarra, P. Miele, S. Zanna, M. Dufond, L. Santinacci and M. Bechelany, Nanomaterials, 2018, 8, 849 .

Q. Weng, X. Wang, C. Zhi, Y. Bando and D. Golberg, ACS Nano, 2013, 7, 1558-1565.

J. Li, J. Lin, X. Xu, X. Zhang, Y. Xue, J. Mi, Z. Mo, Y. Fan, L. Hu and X. Yang, Nanotechnology, 2013, 24, 155603.

Y. Irokawa, Sensors, 2011, 11, 674-695.

M. Ritala, K. Kukli, A. Rahtu, P. I. Räisänen, M. Leskelä, T. Sajavaara and J. Keinonen, Science (80-. )., 2000, 288, 319321.

J. Hämäläinen, M. Ritala and M. Leskelä, Chem. Mater., 2013, 26, 786-801.

H. Kim, J. Vac. Sci. Technol. B Microelectron. Nanom. Struct. Process. Meas. Phenom., 2003, 21, 2231-2261.

M. Weber, B. Koonkaew, S. Balme, I. Utke, F. Picaud, I. latsunskyi, E. Coy, P. Miele and M. Bechelany, ACS Appl. Mater. Interfaces, 2017, 9, 16669-16678.

M. Weber, E. Coy, I. latsunskyi, L. Yate, P. Miele and M. Bechelany, CrystEngComm, 2017, 19, 6089-6094.

T. Aaltonen, M. Ritala, Y.-L. Tung, Y. Chi, K. Arstila, K. Meinander and M. Leskelä, J. Mater. Res., 2004, 19, 33533358.

M. J. Weber, A. J. M. Mackus, M. A. Verheijen, V. Longo, A. A. Bol and W. M. M. Kessels, J. Phys. Chem. C, 2014, 118, 8702.

M. Leskelä and M. Ritala, Thin Solid Films, 2002, 409, 138146.

S. M. George, Chem. Rev., 2010, 110, 111-131. 

Nanostructured Materials, 2012, pp. 41-59.

C. Marichy, M. Bechelany and N. Pinna, Adv. Mater., 2012, 24, 1017-1032.

C. Detavernier, J. Dendooven, S. Pulinthanathu Sree, K. F. Ludwig and J. A. Martens, Chem. Soc. Rev., 2011, 40, 5242 5253. H. Van Bui, F. Grillo and J. R. van Ommen, Chem. Commun., 2017, 53, 45-71.

49 I. J. Raaijmakers, ECS Trans., 2011, 41, 3-17.

G. N. Parsons, S. M. George and M. Knez, MRS Bull., 2011, 36, 865-871. Biosens. Bioelectron., , DOI:10.1016/j.bios.2018.09.038. M. Weber, P. Collot, H. El Gaddari, S. Tingry, M. Bechelany and Y. Holade, ChemElectroChem, 2018, 5, 743-747. A. J. M. Mackus, M. J. Weber, N. F. W. Thissen, D. GarciaAlonso, R. H. J. Vervuurt, S. Assali, A. A. Bol, M. A. Verheijen and W. M. M. Kessels, Nanotechnology, 2016, 27, 034001.

M. Weber, A. Julbe, A. Ayral, P. Miele, M. Bechelany and B. M. Weber M., Julbe A., Ayral A., Miele P., Chem. Mater., , DOI:10.1021/acs.chemmater.8b02687. J. D. Ferguson, A. W. Weimer and S. M. George, Thin Solid Films, 2002, 413, 16-25. B. Mårlid, M. Ottosson, U. Pettersson, K. Larsson and J. O. Carlsson, Thin Solid Films, 2002, 402, 167-171. J. Olander, L. M. Ottosson, P. Heszler, J.-O. Carlsson and K. M. E. Larsson, Chem. Vap. Depos., 2005, 11, 330-337. H. Park, T. K. Kim, S. W. Cho, H. S. Jang, S. I. Lee and S.-Y. Choi, Sci. Rep., 2017, 7, 40091.

A. Hemmi, C. Bernard, H. Cun, S. Roth, M. Klöckner, M. Weinl, S. Gsell, M. Schreck, J. Osterwalder and T. Greber, Rev. Sci. Instrum., 2014, 85, 035101. J. K. Sprenger, H. Sun, A. S. Cavanagh, A. Roshko, P. T. Blanchard and S. M. George, J. Phys. Chem. C, 2018, 122, 9455-9464. M. Weber, I. latsunskyi, E. Coy, P. Miele, D. Cornu and M. Bechelany, Adv. Mater. Interfaces, 2018, 5, 18-56. W. Hao, C. Marichy, C. Journet and A. Brioude, ChemNanoMat, 2017, 3, 656-663. J. W. Elam, A. V. V Zinovev, M. J. Pellin, D. J. Comstock and M. C. Hersam, ECS Trans., 2007, 3, 271-278.

B. J. O'Neill, D. H. K. Jackson, J. Lee, C. Canlas, P. C. Stair, C. L. Marshall, J. W. Elam, T. F. Kuech, J. A. Dumesic and G. W. Huber, ACS Catal., 2015, 5, 1804-1825. J. Lu, J. W. Elam and P. C. Stair, Acc. Chem. Res., 2013, 46 1806-1815.
S. Sun, G. Zhang, N. Gauquelin, N. Chen, J. Zhou, S. Yang, W. Chen, X. Meng, D. Geng and M. N. Banis, Sci. Rep., 2013, 3, 1775.

H. Feng, J. W. Elam, J. A. Libera, W. Setthapun and P. C. Stair, Chem. Mater., 2010, 22, 3133-3142.

J. Lu and P. C. Stair, Angew. Chemie Int. Ed., 2010, 49, 2547-2551.

L. Assaud, N. Brazeau, M. K. S. Barr, M. Hanbücken, S. Ntais, E. A. Baranova and L. Santinacci, ACS Appl. Mater. Interfaces, 2015, 7, 24533-24542.

G. A. Ten Eyck, S. Pimanpang, H. Bakhru, T. Lu and G. Wang, Chem. Vap. Depos., 2006, 12, 290-294.

T. Gong, L. Qin, W. Zhang, H. Wan, J. Lu and H. Feng, J. Phys. Chem. C, 2015, 119, 11544-11556.

E. Rikkinen, A. Santasalo-Aarnio, S. Airaksinen, M. Borghei, V. Viitanen, J. Sainio, E. I. Kauppinen, T. Kallio and A. O. I. Krause, J. Phys. Chem. C, 2011, 115, 23067-23073. X. Liang, L. B. Lyon, Y.-B. Jiang and A. W. Weimer, J. Nanoparticle Res., 2012, 14, 943. M. Drobek, J.-H. Kim, M. Bechelany, C. Vallicari, A. Julbe and S. S. Kim, ACS Appl. Mater. Interfaces, 2016, 8, 83238328.

N. Leick, J. W. Weber, A. J. M. Mackus, M. J. Weber, M. C. M. Van De Sanden and W. M. M. Kessels, J. Phys. D. Appl. Phys., , DOI:10.1088/0022-3727/49/11/115504.

E. Langereis, S. B. S. Heil, H. C. M. Knoops, W. Keuning, M. C. M. Van de Sanden and W. M. M. Kessels, J. Phys. D. Appl. Phys., 2009, 42, 73001.

M. Weber, I. Iatsunskyi, E. Coy, P. Miele, D. Cornu and M. Bechelany, Adv. Mater. Interfaces, , DOI:10.1002/admi.201800056.

M. Weber, E. Coy, I. Iatsunskyi, L. Yate, P. Miele and M. Bechelany, CrystEngComm, , DOI:10.1039/c7ce01357d. M. Weber, J.-H. Kim, J.-H. Lee, J.-Y. Kim, I. latsunskyi, E. Coy, M. Drobek, A. Julbe, M. Bechelany and S. S. Kim, ACS Appl. Mater. Interfaces, 2018, 10, 34765-34773.

S. E. Al Garni and A. F. Qasrawi, Phys. status solidi, 2015, 212, 1845-1850.

H. K. Khanfar, A. F. Qasrawi and Y. K. Ghannam, Act. Passiv. Electron. Components.

S. Halas and T. Durakiewicz, Vacuum, 2010, 85, 486-488. V. Singh, S. Dhall, A. Kaushal and B. R. Mehta, Int. J. Hydrogen Energy, 2018, 43, 1025-1033. C. W. Hamilton, R. T. Baker, A. Staubitz and I. Manners, Chem. Soc. Rev., 2009, 38, 279-293. R. Shahsavari and S. Zhao, Small, 2018, 14, 1702863. 